\title{
The electrophysiological effects of cannabidiol on action potentials and transmembrane potassium currents in rabbit and dog cardiac ventricular preparations
}

\author{
Leila Topal ${ }^{1} \cdot$ Muhammad Naveed $^{1} \cdot$ Péter Orvos $^{1} \cdot$ Bence Pászti $^{1}$ - János Prorok ${ }^{2}$ - Ákos Bajtel ${ }^{3}$. Tivadar Kiss ${ }^{3}$. \\ Boglárka Csupor-Löffler ${ }^{4}$. Dezső Csupor ${ }^{3,4}$. István Baczkó ${ }^{1,5}$. András Varró ${ }^{1,2,5}$ • László Virág ${ }^{1,5}$. Norbert Jost ${ }^{1,2}$ (1)
}

Received: 7 April 2021 / Accepted: 17 May 2021 / Published online: 24 May 2021

(c) The Author(s) 2021

\begin{abstract}
Cannabis use is associated with known cardiovascular side effects such as cardiac arrhythmias or even sudden cardiac death. The mechanisms behind these adverse effects are unknown. The aim of the present work was to study the cellular cardiac electrophysiological effects of cannabidiol (CBD) on action potentials and several transmembrane potassium currents, such as the rapid $\left(\mathrm{I}_{\mathrm{Kr}}\right)$ and slow $\left(\mathrm{I}_{\mathrm{Ks}}\right)$ delayed rectifier, the transient outward $\left(\mathrm{I}_{\mathrm{to}}\right)$ and inward rectifier $\left(\mathrm{I}_{\mathrm{K} 1}\right)$ potassium currents in rabbit and dog cardiac preparations. CBD increased action potential duration (APD) significantly in both rabbit (from $211.7 \pm 11.2$. to $224.6 \pm 11.4 \mathrm{~ms}, n=8$ ) and $\operatorname{dog}$ (from $215.2 \pm 9.0$ to $231.7 \pm 4.7 \mathrm{~ms}, n=6$ ) ventricular papillary muscle at $5 \mu \mathrm{M}$ concentration. CBD decreased $\mathrm{I}_{\mathrm{Kr}}, \mathrm{I}_{\mathrm{Ks}}$ and $\mathrm{I}_{\mathrm{to}}$ (only in dog) significantly with corresponding estimated $\mathrm{EC}_{50}$ values of $4.9,3.1$ and $5 \mu \mathrm{M}$, respectively, without changing $\mathrm{I}_{\mathrm{K} 1}$. Although the $\mathrm{EC}_{50}$ value of CBD was found to be higher than literary $\mathrm{C}_{\max }$ values after CBD smoking and oral intake, our results raise the possibility that potassium channel inhibition by lengthening cardiac repolarization might have a role in the possible proarrhythmic side effects of cannabinoids in situations where CBD metabolism and/or the repolarization reserve is impaired.
\end{abstract}

Keywords Cannabidiol $\cdot$ Electrophysiology $\cdot$ Action potential $\cdot$ Potassium currents $\cdot$ Rabbit $\cdot$ Dog

\section{Introduction}

Leila Topal and Muhammad Naveed are contributed equally to this manuscript, both considered to be first author.

László Virág and Norbert Jost shared senior authorship.

Norbert Jost

jost.norbert@med.u-szeged.hu

1 Department of Pharmacology and Pharmacotherapy, Faculty of Medicine, University of Szeged, Dóm tér 12, 6720 Szeged, Hungary

2 ELKH-SZTE Research Group for Cardiovascular Pharmacology, Eötvös Loránd Research Network, Szeged, Hungary

3 Department of Pharmacognosy, Faculty of Pharmacy, University of Szeged, Szeged, Hungary

4 Institute for Translational Medicine, Medical School, University of Pécs, Pécs, Hungary

5 Department of Pharmacology and Pharmacotherapy, Interdisciplinary Excellence Centre, University of Szeged, 6720 Szeged, Hungary
Cannabis has been one of the most abused hallucinogenic drugs since ancient times with an estimated 150 million consumers worldwide (Kalla et al. 2018). Moreover, the increasingly widespread use of e-cigarettes, the number of people inhaling cannabinoids might even be higher. In addition, the use of cannabis products for medicinal purposes is increasing globally. The enhanced general interest for the use of cannabis and cannabis-derived products was facilitated following the discovery of the cannabinoid system in humans (Sierra et al. 2018). The subsequent new findings on biological actions of cannabinoids on the central nervous system and immune functions attracted further attention. At present, there are cannabis-based drugs on the market with well-defined indications, including treatment of nausea and vomiting following chemotherapy, anorexia, pain related to cancer, spasticity and pain associated with multiple sclerosis, and Dravet and Lennox-Gastaut syndromes (FraguasSánchez and Torres-Suárez 2018). These drugs contain known amounts of CBD and/or THC in pure form or as 
herbal extract (Fraguas-Sánchez and Torres-Suárez 2018). In addition to the use of CBD-containing products, CBD oil is very common with several, clinically unsupported indications. The consumption of cannabinoids, particularly CBD, which is enriched in numerous products, can be higher in case of the intake of CBD oils than in case of smoking cannabis. The consumption of cannabinoids, particularly CBD, which is enriched in numerous products, can be higher in case of the intake of CBD oils than in case of smoking cannabis. At high temperature, the majority of CBD is broken down (Czégény et al. 2021), whilst from CBD oils (in fact $\mathrm{CBD}$ dissolved in vegetable oils) containing up to $20 \% \mathrm{CBD}$, a significant amount of CBD is absorbed.

The possible cardiovascular side effects of cannabinoid use have been indicated in several reports, ranging from arrhythmias to myocardial infarction and even sudden cardiac death (Pacher et al. 2018). According to a cohort study, marijuana smokers can have a 4.8 -fold increase of risk developing acute myocardial infarction following the first hour of cannabinoid exposure (Mittleman et al. 2001). On the other hand, other reports do not support the link between cannabis use and cardiovascular events (Singh et al. 2019). Accordingly, an important comprehensive study assessed data for 316,397 cannabis users and 20,499,215 non-users found that cannabis use was an independent predictor of heart failure (Kalla et al. 2018). Although the mechanisms explaining these observations are poorly understood, the effects of cannabinoids exerted via the G protein-coupled cannabinoid receptors are suspected to play key roles. In addition, numerous studies reported proarrhythmic properties of cannabinoids including ventricular arrhythmias and even sudden cardiac death (Courts et al. 2016; Ozturk et al. 2019; Manolis et al. 2019). However, the mechanism of these arrhythmias remains unclear (Ozturk et al. 2019). It was reported earlier and also recently that certain voltagegated ion channels like cardiac sodium, calcium (Al Kury et al. 2014), hERG and Kv4.3 channels (Amoros et al. 2010) might be also related to the reported cardiac effects of cannabinoids, but the possible effects of CBD on various cardiac potassium currents which play a crucial role in cardiac repolarization have not been studied yet in detail. Such transmembrane ion currents in cardiac ventricular muscle are the rapid $\left(\mathrm{I}_{\mathrm{Kr}}\right)$ and slow $\left(\mathrm{I}_{\mathrm{Ks}}\right)$ delayed rectifier potassium currents, the transient outward $\left(\mathrm{I}_{\mathrm{to}}\right)$ and inward rectifier $\left(\mathrm{I}_{\mathrm{K} 1}\right)$ potassium currents, all important for cardiac repolarization. Several cardiac and non-cardiac drugs are known to inhibit $\mathrm{I}_{\mathrm{Kr}}$ (also called hERG ion channel) and consequently they prolong cardiac QT interval and enhance dispersion of repolarization. The latter has been associated with the development of life-threatening arrhythmias. Therefore, the official drug development procedure requires an early screening of whether a potential drug candidate has any activities on the hERG channels (Sanguinetti and Tristani-Firouzi 2006).
However, drug effects on cardiac repolarization cannot be accurately estimated by measuring hERG channel and currents (Orvos et al. 2019), since drugs can also affect cardiac repolarization and action potential by acting on different currents other than hERG or $\mathrm{I}_{\mathrm{Kr}}$.

Therefore, in the present study the aim was to investigate the effect of CBD, a major cannabinoid, on cardiac ventricular action potential and on several cardiac transmembrane currents to provide further experimental data for the elucidation of the possible mechanisms of its adverse cardiac electrophysiological effects.

\section{Methods}

\section{Animals and materials}

All experiments were carried out in compliance with the Guide for the Care and Use of Laboratory Animals (USA NIH publication NO 85-23, revised 1996) and conformed to the Directive 2010/63/EU of the European Parliament. The protocols have been approved by the Ethical Committee for the Protection of Animals in Research of the University of Szeged, Szeged, Hungary (approval numbers: I-74-15-2017 and I-74-24-2017) and by the Department of Animal Health and Food Control of the Ministry of Agriculture and Rural Development (authority approval numbers XIII/3330/2017 and XIII/3331/2017).

\section{Conventional microelectrode technique}

Action potentials were recorded in right ventricular trabecular or papillary muscle preparations obtained from dog or rabbit hearts using conventional microelectrode techniques as described earlier in detail (Jost et al. 2013; Orvos et al. 2019).

Preparations were individually mounted in a tissue chamber with a volume of $50 \mathrm{ml}$. During experiments modified Locke's solution was used, containing (in $\mathrm{mM}$ ): $\mathrm{NaCl}$ 128.3, $\mathrm{KCl} 4, \mathrm{CaCl}_{2} 1.8, \mathrm{MgCl}_{2} 0.42, \mathrm{NaHCO}_{3} 21.4$ and glucose 10. The $\mathrm{pH}$ of this solution was set between 7.35 and 7.4 when gassed with the mixture of $95 \% \mathrm{O}_{2}$ and $5 \% \mathrm{CO}_{2}$ at $37{ }^{\circ} \mathrm{C}$. Each preparation was stimulated through a pair of platinum electrodes in contact with the preparation using rectangular current pulses of 1-3 ms duration at twice of the threshold strength at a constant basic cycle length of $1000 \mathrm{~ms}$ for ventricular preparations. These stimuli were delivered for at least $60 \mathrm{~min}$ allowing the preparation to equilibrate before the measurements were initiated. Transmembrane potentials were recorded using conventional glass microelectrodes, filled with $3 \mathrm{M} \mathrm{KCl}$ and having tip resistances of 5-20 M $\Omega$, connected to the input of a high 
impedance electrometer (Experimetria, type 309, Budapest, Hungary) which was coupled to a dual beam oscilloscope.

The resting potential (RP), action potential amplitude (APA), maximum upstroke velocity $\left(\mathrm{V}_{\max }\right)$ and APD measured at $50 \%$ and $90 \%$ of repolarization $\left(\mathrm{APD}_{50}\right.$ and $\mathrm{APD}_{90}$, respectively) were determined off-line using an in-house developed software (APES) running on a computer equipped with an ADA 3300 analogue-to-digital data acquisition board (Real Time Devices, Inc., State College, Pennsylvania) having a maximum sampling frequency of $40 \mathrm{kHz}$.

Attempts were made to maintain the same impalement throughout each experiment. In case an impalement became dislodged, adjustment was attempted, and if the action potential characteristics of the re-established impalement deviated by less than $5 \%$ from the previous measurement, the experiment continued.

\section{Voltage-clamp measurements}

Ventricular myocytes were enzymatically dissociated from canine or rabbit hearts as described earlier in detail (Jost et al. 2013; Orvos et al. 2019). One drop of cell suspension was placed in a transparent recording chamber mounted on the stage of an inverted microscope (Olympus IX51, Olympus, Tokyo, Japan), and individual myocytes were allowed to settle and adhere to the chamber bottom for at least 5-10 $\mathrm{min}$ before superfusion was initiated and maintained by gravity. Only rod-shaped cells with clear striations were used. HEPES-buffered Tyrode's solution (composition in $\mathrm{mM}$ : $\mathrm{NaCl} 144, \mathrm{NaH}_{2} \mathrm{PO}_{4} 0.4, \mathrm{KCl} 4.0, \mathrm{CaCl}_{2} 1.8, \mathrm{MgSO}_{4} 0.53$, glucose 5.5 and HEPES 5.0, at pH of 7.4) served as the normal superfusate.

Micropipettes were fabricated from borosilicate glass capillaries (Science Products GmbH, Hofheim, Germany), using a P-97 Flaming/Brown micropipette puller (Sutter Co, Novato, CA, USA), and had a resistance of 1.5-2.5 MOhm when filled with pipette solution. The membrane currents were recorded with Axopatch-200B amplifiers (Molecular Devices, Sunnyvale, CA, USA) by means of the whole-cell configuration of the patch-clamp technique. The membrane currents were digitized with $250 \mathrm{kHz}$ analogue-to-digital converters (Digidata 1440A, Molecular Devices, Sunnyvale, CA, USA) under software control (pClamp 10, Molecular Devices, Sunnyvale, CA, USA). Experiments were carried out at $37^{\circ} \mathrm{C}$.

\section{Measurement of potassium currents}

The inward rectifier $\left(\mathrm{I}_{\mathrm{K} 1}\right)$, transient outward $\left(\mathrm{I}_{\mathrm{to}}\right)$, rapid $\left(\mathrm{I}_{\mathrm{Kr}}\right)$ and slow $\left(\mathrm{I}_{\mathrm{Ks}}\right)$ delayed rectifier potassium currents were recorded in HEPES-buffered Tyrode's solution. The composition of the pipette solution (in $\mathrm{mM}$ ) was the following: $\mathrm{KOH} 110, \mathrm{KCl} 40, \mathrm{~K}_{2} \mathrm{ATP} 5, \mathrm{MgCl}_{2}$ 5, EGTA 5 and
HEPES 10 (pH was adjusted to 7.2 by aspartic acid). $1 \mu \mathrm{M}$ nisoldipine was added to the bath solution to block $\mathrm{I}_{\mathrm{CaL}}$. When $\mathrm{I}_{\mathrm{Kr}}$ was recorded $\mathrm{I}_{\mathrm{Ks}}$ was inhibited using the selective $\mathrm{I}_{\mathrm{Ks}}$ blocker HMR $1556(0.5 \mu \mathrm{M})$. During $\mathrm{I}_{\mathrm{Ks}}$ measurements (a transmembrane current strongly depending from cAMP and protein kinase A, PKA; Christian et al. 2011), $\mathrm{I}_{\mathrm{Kr}}$ was blocked by $0.5 \mu \mathrm{M}$ dofetilide and the bath solution contained $0.1 \mu \mathrm{M}$ forskolin.

\section{Data analysis}

All data are expressed as means \pm SEM. The " $n$ " number refers to the number of experiments (i.e. the number of cells in case of patch-clamp and the number of ventricular muscle preparations - papillary or trabecular muscle-in case of action potential measurements). Statistical analysis was performed with Student's $t$ test for paired data. The results were considered statistically significant when $P$ was $<0.05$.

\section{Results}

The cardiac cellular electrophysiological effect of CBD was studied on various transmembrane ionic currents by the whole-cell configuration of the patch-clamp technique in native rabbit and dog ventricular myocytes and on action potentials in rabbit and dog ventricular papillary muscles by the conventional microelectrode technique. Figure 1 and Table 1 show that CBD lengthens action potential duration $\left(\mathrm{APD}_{90}\right)$ significantly at the concentration of $5 \mu \mathrm{M}$ without changing other action potential parameters significantly.

Whole-cell patch-clamp experiments in rabbit cardiac ventricular myocytes revealed significant inhibition of the rapid delayed rectifier potassium current $\left(\mathrm{I}_{\mathrm{Kr}}\right)$ (Figs. 2A and 3 ) with an estimated $\mathrm{EC}_{50}$ value of $4.9 \mu \mathrm{M}$. $\mathrm{I}_{\mathrm{Kr}}$ was activated by $1000 \mathrm{~ms}$ long depolarizing voltage pulses with pulse frequency of $0.05 \mathrm{~Hz}$ to the potentials ranging from $-30 \mathrm{mV}$ to $50 \mathrm{mV}$ and then the cell was repolarized to $-40 \mathrm{mV}$. The deactivating tail current at $-40 \mathrm{mV}$ after the test pulse was assessed as $\mathrm{I}_{\mathrm{Kr}}$. The holding potential was $-80 \mathrm{mV}$.

In similar experiments in rabbit myocytes $\mathrm{CBD}$ depressed the slow delayed rectifier potassium current $\left(\mathrm{I}_{\mathrm{Ks}}\right.$, Fig. 2B) with an estimated $\mathrm{EC}_{50}$ value of $3.1 \mu \mathrm{M}$ (Fig. 4), after $20 \mathrm{mV}$ $5 \mathrm{~s}$ long test pulse measured at $-40 \mathrm{mV}$. $\mathrm{I}_{\mathrm{Ks}}$ was recorded similarly to $\mathrm{I}_{\mathrm{Kr}}$. After $5 \mathrm{~s}$ long depolarizing voltage pulses to various test potentials with pulse frequency of $0.1 \mathrm{~Hz}$ the cell was repolarized to $-40 \mathrm{mV}$ and the tail current amplitude was measured.

CBD even in the high concentration of $10 \mu \mathrm{M}$ concentration did not influence the transient outward potassium current $\left(\mathrm{I}_{\text {to }}\right)$ in rabbit (Fig. 5A) but decreased it significantly in dog (Fig. 5B) ventricular myocytes with an estimated $\mathrm{EC}_{50}$ value of $5 \mu \mathrm{M}$ (Fig. 6). $\mathrm{I}_{\text {to }}$ was activated by $300 \mathrm{~ms}$ long depolarizing 

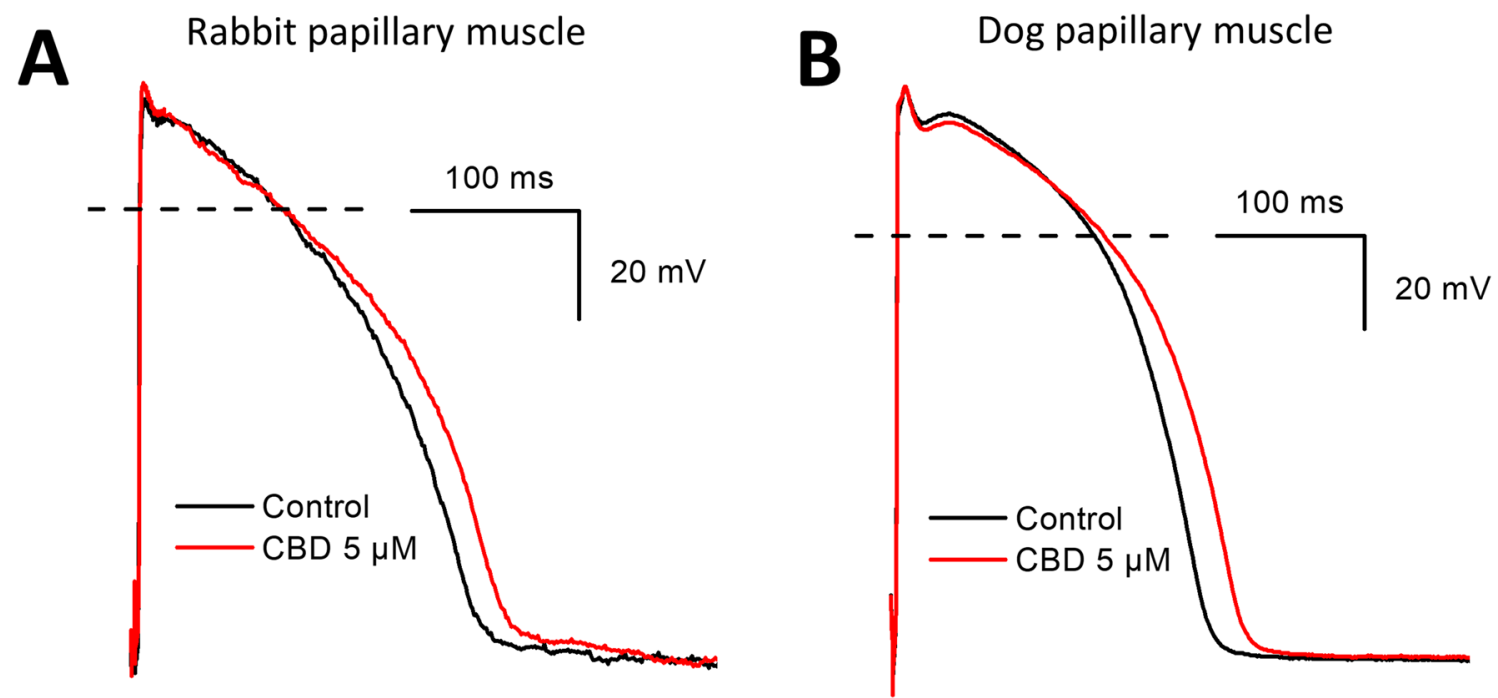

Fig. 1 Effect of CBD on the action potentials recorded from rabbit (panel A) and dog (panel $\mathbf{B}$ ) papillary muscles. Dashed lines indicate zero $\mathrm{mV}$ levels

Table 1 Effect of acute exposure to $\mathrm{CBD}$ on the action potential parameters in rabbit and dog right ventricular papillary muscle preparations

\begin{tabular}{llllll}
\hline Parameters & \multicolumn{2}{l}{$\begin{array}{l}\text { Rabbit ventricular muscle } \\
(n=8)\end{array}$} & & \multicolumn{2}{l}{$\begin{array}{l}\text { Dog ventricular muscle } \\
(n=6)\end{array}$} \\
\cline { 2 - 3 } \cline { 5 - 6 } & Control & CBD 5 $\mu \mathrm{M}$ & & Control & CBD 5 $\mu \mathrm{M}$ \\
\hline $\mathrm{RP}(\mathrm{mV})$ & $-84.1 \pm 2.2$ & $-82.7 \pm 1.7$ & $-84.7 \pm 1.7$ & $-84.7 \pm 2.3$ \\
$\mathrm{APA}(\mathrm{mV})$ & $105.2 \pm 3.0$ & $106.4 \pm 3.0$ & & $118.4 \pm 3.3$ & $120.4 \pm 2.2$ \\
$\mathrm{~V}_{\text {max }}(\mathrm{V} / \mathrm{s})$ & $120.3 \pm 20.6$ & $113.0 \pm 17.1$ & & $186.4 \pm 21.7$ & $201.0 \pm 25.2$ \\
$\mathrm{APD}_{50}(\mathrm{~ms})$ & $171.8 \pm 13.6$ & $\mathbf{1 8 3 . 0} \pm \mathbf{1 2 . 8}$ & & $178.3 \pm 8.2$ & $193.1 \pm 4.5$ \\
$\mathrm{APD}_{90}(\mathrm{~ms})$ & $211.7 \pm 11.2$ & $\mathbf{2 2 4 . 6} \pm \mathbf{1 1 . 4}$ & & $215.2 \pm 9.0$ & $\mathbf{2 3 1 . 7} \pm \mathbf{4 . 7}$ \\
\hline
\end{tabular}

Bold values are considered to be statistically significant $(P<0.05$ versus control)

$P<0.05$ versus control

$R P$ resting membrane potential, $A P A$ action potential amplitude, $V_{\max }$ maximum upstroke velocity

$\mathrm{APD}_{50}$ and $\mathrm{APD}_{90}$ action potential duration measured at 50 and $90 \%$ of repolarization

voltage pulses arising from the holding potential of $-90 \mathrm{mV}$ to test potentials gradually increasing up to $50 \mathrm{mV}$. The pulse frequency was $0.33 \mathrm{~Hz}$.

As Fig. 7 indicates, CBD did not significantly change the inward rectifier potassium current $\left(\mathrm{I}_{\mathrm{K} 1}\right)$ even at the high, $10 \mu \mathrm{M}$ concentration. $\mathrm{I}_{\mathrm{K} 1}$ current was measured as the steady-state current level at the end of the $300 \mathrm{~ms}$ long voltage pulse in the voltage range of -100 to $0 \mathrm{mV}$ with a pulse frequency of $0.33 \mathrm{~Hz}$. The holding potential was $-90 \mathrm{mV}$.

\section{Discussion}

The main result of this study is that $5 \mu \mathrm{M}$ CBD prolongs repolarization. This effect on repolarization in rabbit and dog papillary muscle can be best explained by the multiple effects CBD exerts on various potassium channels. Accordingly, as our previous results (Orvos et al. 2020) indicated, CBD administration at lower concentrations $(1,2.5$ and $5 \mu \mathrm{M})$ resulted in $\mathrm{hERG} / \mathrm{I}_{\mathrm{Kr}}$ depression and a consequent lengthening of $\mathrm{APD}_{90}$, but this effect was counterbalanced by the inhibition of inward $\mathrm{Ca}^{2+}$ and $\mathrm{Na}^{+}$ currents following CBD application at the high concentration of $10 \mu \mathrm{M}$. Similar effects were reported earlier with quinidine, an antiarrhythmic drug, with established proarrhythmic properties (Roden and Hoffman 1985; Varro et al. 1985).

A few previous studies with cannabinoids showed effects on various transmembrane ion channels such as inward sodium, (Al Kury et al. 2014; Ghovanloo et al. 2018; Orvos et al. 2020) inward calcium (Al Kury et al. 2014; Orvos et al. 2020), outward transient current ( $\mathrm{Li}$ et al. 2012) and human Kv1.5 and Kv4.3 channels (Barana et al. 2010). In addition, in previous studies (Orvos et al. 2020) $\mathrm{hERG} / \mathrm{I}_{\mathrm{Kr}}$ channel inhibition and QT prolongation were also reported in anaesthetized rats (Yun et al. 2016) and guinea pig (Orvos et al. 2020) by a synthetic cannabinoid compound (JWH-030) and CBD. This synthetic cannabinoid compound structurally differs from CBDs and inhibited hERG channels with a relatively high $\mathrm{EC}_{50}$ 


\section{Rabbit left ventricular myocytes}

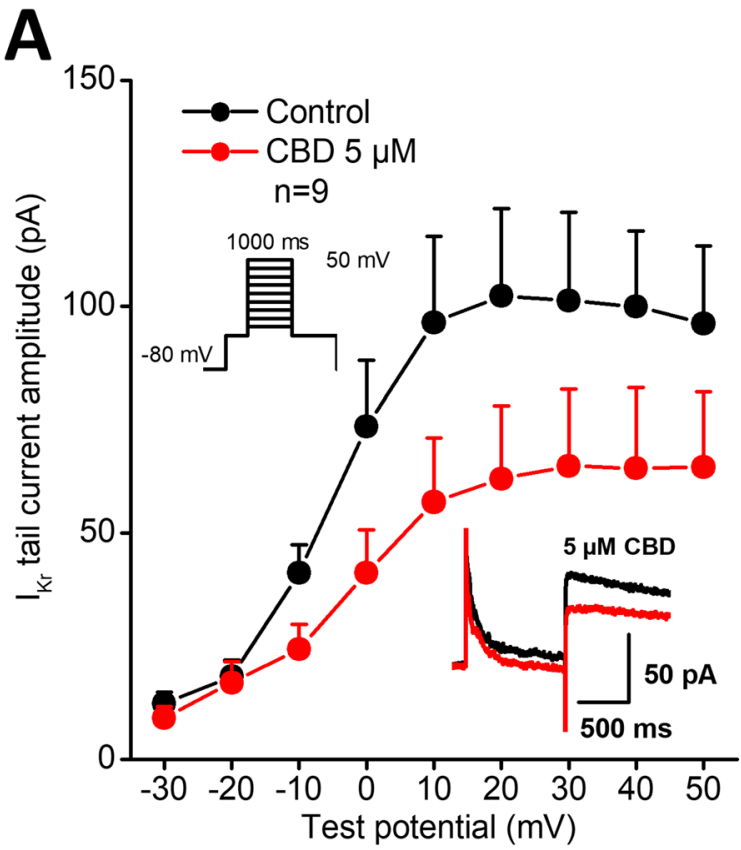

Fig. 2 Effect of $\mathrm{CBD}$ on the rapid $\left(\mathrm{I}_{\mathrm{Kr}}\right)$ and slow $\left(\mathrm{I}_{\mathrm{Ks}}\right)$ delayed rectifier potassium currents. Panels show current-voltage curves for $\mathrm{I}_{\mathrm{Kr}}$ (panel A) and for $\mathrm{I}_{\mathrm{Ks}}$ (panel B) in control conditions and after appli-

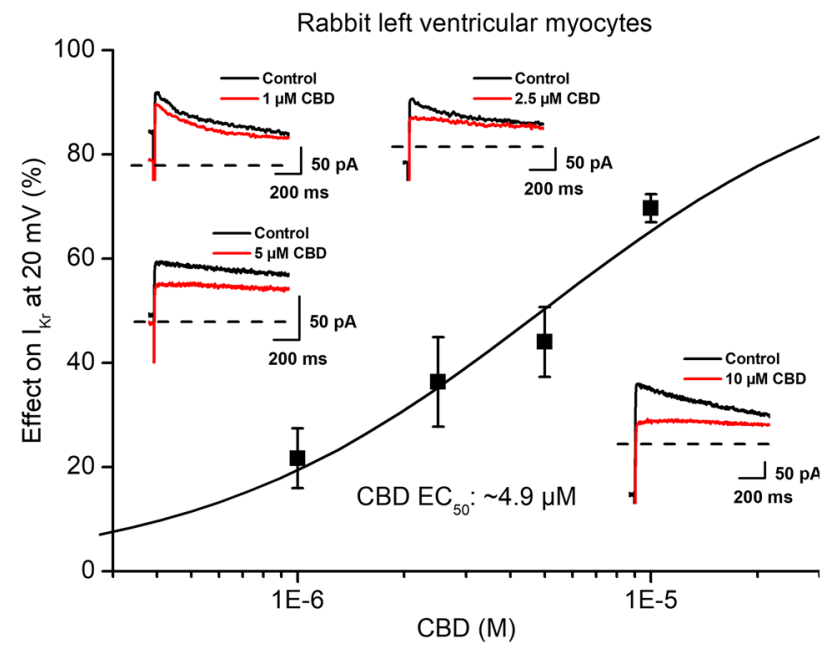

Fig. 3 Effect of $\mathrm{CBD}$ on the rapid $\left(\mathrm{I}_{\mathrm{Kr}}\right)$ delayed rectifier potassium currents. The panel displays CBD concentration-response curve indicating an estimated $\mathrm{EC}_{50}$ value of $4.9 \mu \mathrm{M}$ for $\mathrm{I}_{\mathrm{Kr}}$ blockade. The insets show the tail current section of original $\mathrm{I}_{\mathrm{Kr}}$ current traces in control conditions and in the presence of $1 \mu \mathrm{M}, 2.5 \mu \mathrm{M}, 5 \mu \mathrm{M}$ and $10 \mu \mathrm{M}$ $\mathrm{CBD}$ recorded from rabbit left ventricular myocytes after a $1 \mathrm{~s}$ long pulse to $20 \mathrm{mV}$ test potential with pulsing cycle length of $20 \mathrm{~s}$. $\mathrm{I}_{\mathrm{Kr}}$ deactivating tail current was measured at $-40 \mathrm{mV}$. The dashed lines refer to the baseline for $\mathrm{I}_{\mathrm{Kr}}$ tail current level after the test pulse at $-40 \mathrm{mV}$. Data are expressed as means $\pm \mathrm{SEM}$
B

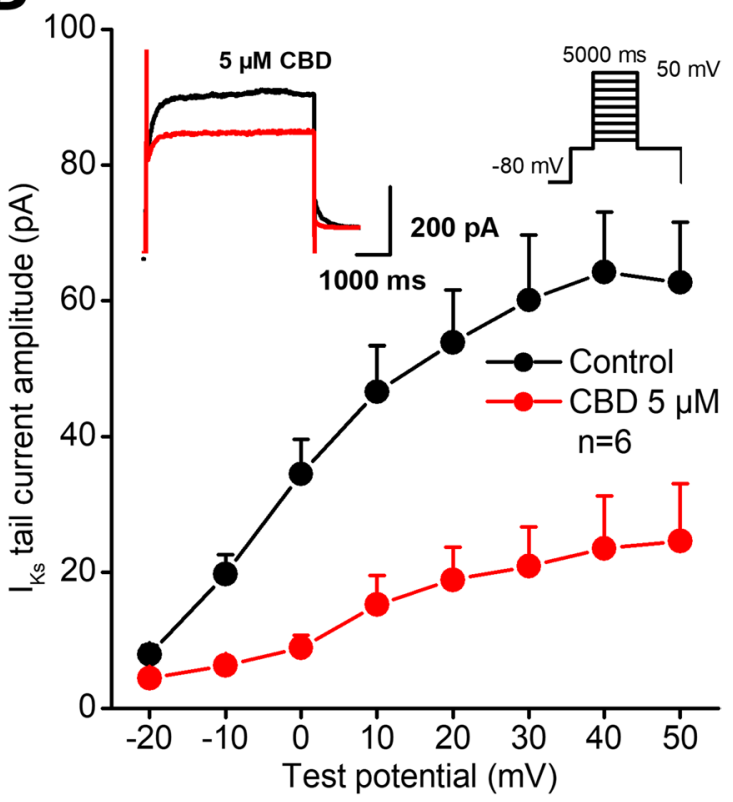

cation of $5 \mu \mathrm{M}$ CBD. Insets indicate the voltage protocols and original $\mathrm{I}_{\mathrm{Kr}}$ and $\mathrm{I}_{\mathrm{KS}}$ current records in control and in the presence of CBD. Data are expressed as means \pm SEM

$(88.36 \mu \mathrm{M})$. Also, in rat ventricle $\mathrm{hERG} / \mathrm{I}_{\mathrm{Kr}}$ seems not as important for controlling repolarization as $\mathrm{Kv} 4.2$ and Kv1.5 channels. Therefore, the cannabinoid-evoked QT changes in rat most likely can be attributed to Kv1.5 and Kv4.2 rather than hERG channel inhibition. The finding of the present study that CBD inhibits $\mathrm{I}_{\text {to }}$ in dog but not in rabbit ventricular myocytes are in good agreement with the previously mentioned rat study, since in $\operatorname{dog} \mathrm{I}_{\text {to }}$ is conducted $\mathrm{Kv} 4.3$ (Han et al. 2002) but in rabbit by $\mathrm{Kv}$ 1.4 channels (Wang et al. 1999). Since the APD measurements in the present study were taken in subendocardial preparations, the latter effect on $\mathrm{I}_{\text {to }}$ may result in more pronounced repolarization dispersion in dog and human ventricle where in midmyocardial cells $I_{\text {to }}$ is greater than in the subendocardium (Zicha et al. 2004).

According to human pharmacokinetic data, the $\mathrm{C}_{\max }$ values for $\mathrm{CBD}$ can reach $0.35 \mu \mathrm{M}$ and $0.58 \mu \mathrm{M}$ during CBD smoking (19.2 mg) or following oral administration (400 mg), respectively (Millar et al. 2018). In the present experiments, CBD had inhibitory potency on both the hERG channel and $\mathrm{I}_{\mathrm{Kr}}$ activity, with an $\mathrm{EC}_{50}$ value higher than literary $\mathrm{C}_{\max }$ values in patients. This suggests small or negligible proarrhythmic risk in physiological conditions in healthy individuals. This is indeed in good agreement 


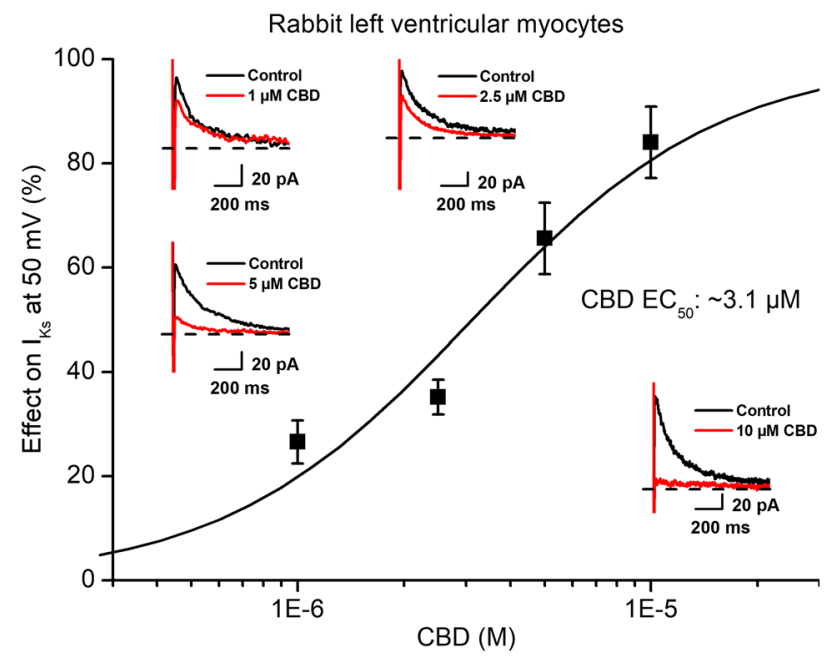

Fig. 4 Effect of $\mathrm{CBD}$ on the slow $\left(\mathrm{I}_{\mathrm{Ks}}\right.$ ) delayed rectifier potassium currents. The panel displays CBD concentration-response curve indicating an estimated $\mathrm{EC}_{50}$ value of $3.1 \mu \mathrm{M}$ for $\mathrm{I}_{\mathrm{Ks}}$ blockade. The insets show the tail current section of original $\mathrm{I}_{\mathrm{Ks}}$ current traces in control conditions and in the presence of $1 \mu \mathrm{M}, 2.5 \mu \mathrm{M}, 5 \mu \mathrm{M}$ and $10 \mu \mathrm{M}$ CBD recorded from rabbit left ventricular myocytes after a $5 \mathrm{~s}$ long pulse to $50 \mathrm{mV}$ test potential with pulsing cycle length of $10 \mathrm{~s}$. $\mathrm{I}_{\mathrm{Ks}}$ deactivating tail current was measured at $-40 \mathrm{mV}$. The dashed lines refer to the baseline for $\mathrm{I}_{\mathrm{Ks}}$ tail current level after the test pulse at $-40 \mathrm{mV}$. Data are expressed as means \pm SEM

A

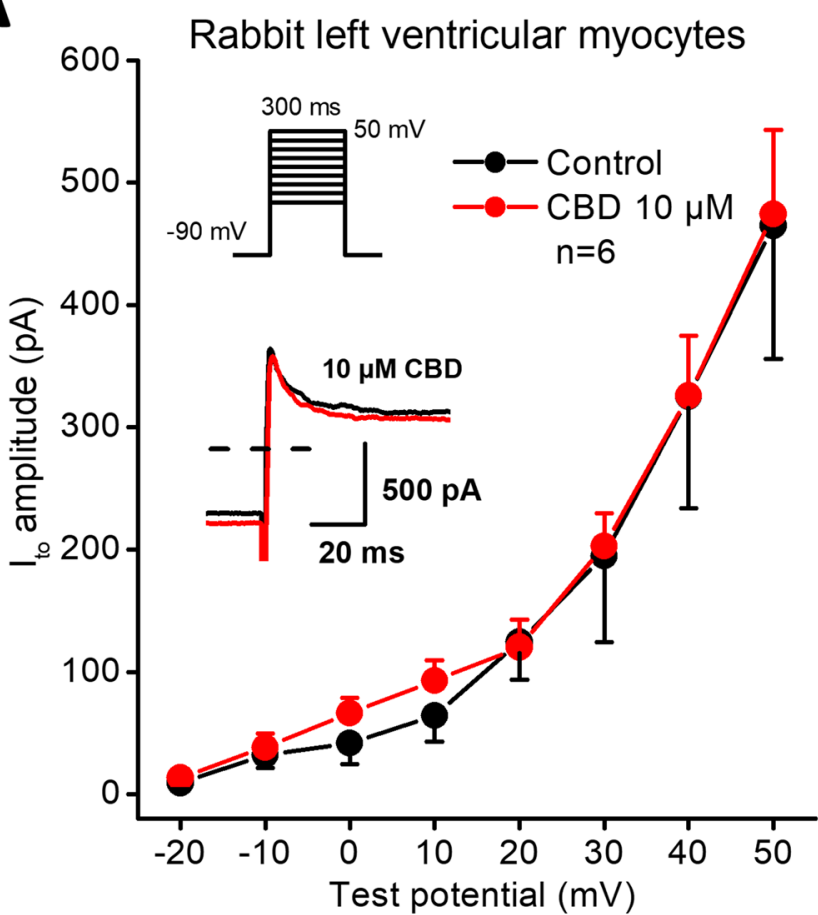

Fig. 5 Effect of CBD on the transient outward potassium current $\left(\mathrm{I}_{\mathrm{to}}\right)$ in rabbit and dog ventricular myocytes. Panels show current-voltage curves for $\mathrm{I}_{\text {to }}$ in control conditions and after application of CBD in rabbit (panel A) and in dog (panel B) ventricular myocytes. Insets with clinical reports showing no significant $\mathrm{QT}_{\mathrm{c}}$ prolongation in patients after CBD administration (Sellers et al. 2013). Also, in another clinical study, it was found that long term Sativex (THC + CBD) treatment evoked T wave changes in only 1 out of 146 patients (Serpell et al. 2013). Therefore, it is likely that in case of inhalation or oral use of cannabis-derived products, CBD itself may not represent a significant proarrhythmic risk. Based on the comparison of hERG or $\mathrm{I}_{\mathrm{Kr}}$ activity, cardiac action potential duration, and QT prolongation against QT effects and reports of arrhythmogenic (torsade de pointes) potential of 100 drugs, a margin of 30 -fold between hERG $\mathrm{EC}_{50}$ and $\mathrm{C}_{\max }$ was proposed to be an acceptable degree of safety regarding arrhythmogenesis (Redfern et al. 2003). Taking into account the $\mathrm{EC}_{50}$ values for $\mathrm{I}_{\mathrm{Kr}}, \mathrm{I}_{\mathrm{Ks}}$ and $\mathrm{I}_{\mathrm{to}}$ inhibition in our experiments $(4.9,3.1$ and $5 \mu \mathrm{M}$, respectively), the ratios of $\mathrm{EC}_{50}$ and $\mathrm{C}_{\max }$ values are in the range of about 8-9, which refers to moderately increased risk of arrhythmia. However, in patients who have considerably slower drug elimination due to certain concomitant diseases or in case of concurrent use of other drugs that inhibit the metabolism of CBD, higher $\mathrm{C}_{\max }$ values can develop (Iffland and Grotenhermen

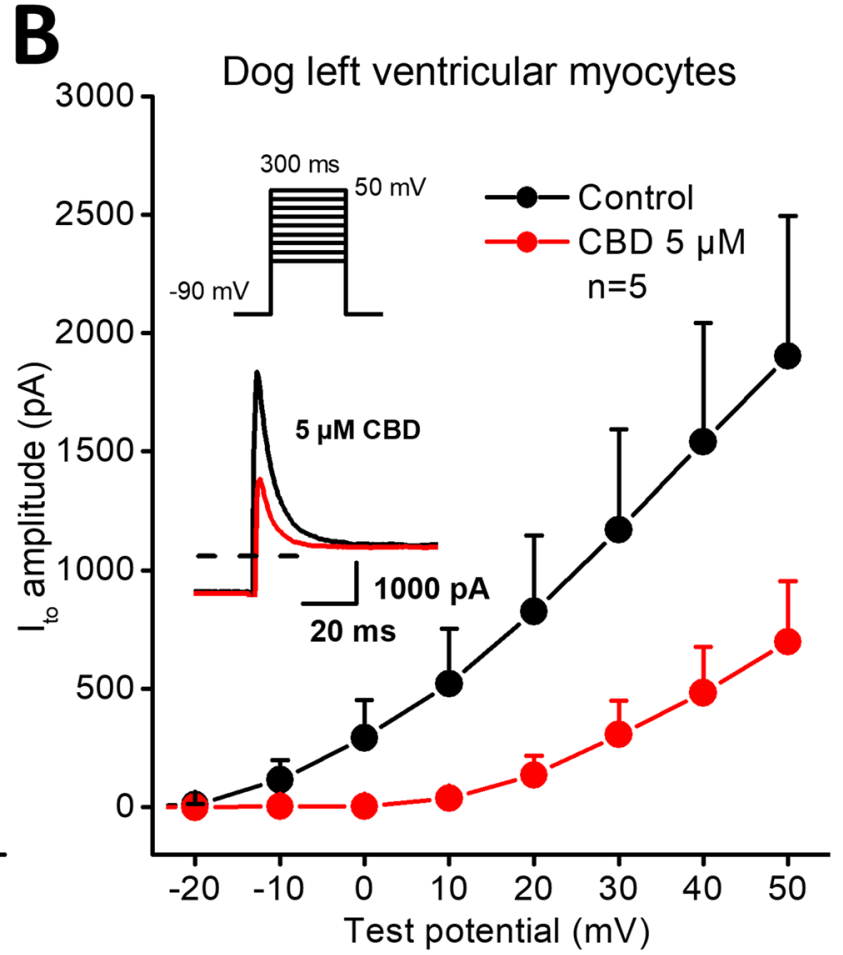

indicate the voltage protocols and original $\mathrm{I}_{\mathrm{to}}$ current records in control and in the presence of CBD. Dashed lines indicate zero current levels. Data are expressed as means \pm SEM 


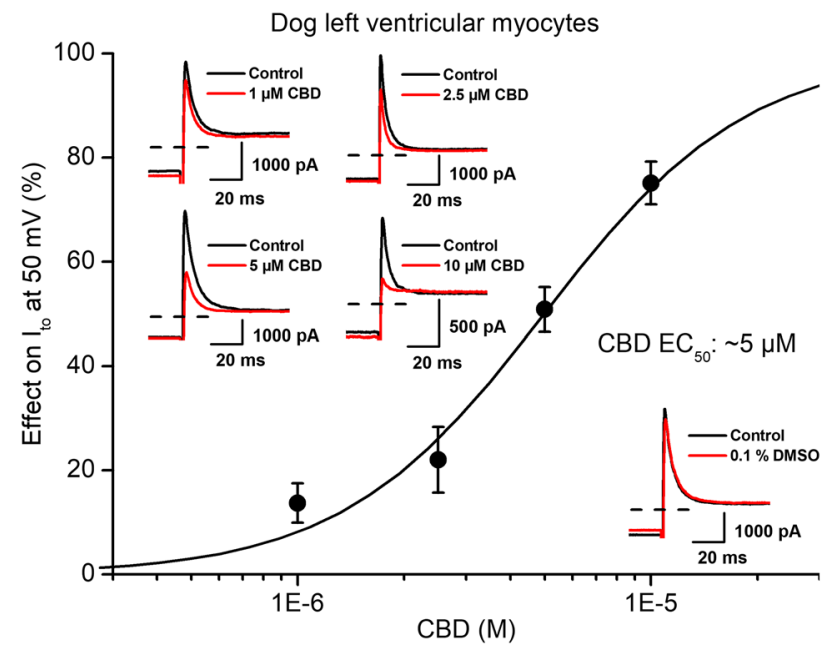

Fig. 6 Effect of CBD on the transient outward potassium current $\left(\mathrm{I}_{\mathrm{to}}\right)$ in dog ventricular myocytes. The panel displays CBD concentration-response curve indicating an estimated $\mathrm{EC}_{50}$ value of $5 \mu \mathrm{M}$ for $\mathrm{I}_{\text {to }}$ blockade. Insets show original $\mathrm{I}_{\text {to }}$ current traces in control conditions and in the presence of $1 \mu \mathrm{M}, 2.5 \mu \mathrm{M}, 5 \mu \mathrm{M}$ and $10 \mu \mathrm{M}$ CBD recorded from dog left ventricular myocytes after a $300 \mathrm{~ms}$ long pulse to $50 \mathrm{mV}$ test potential with pulsing cycle length of $3 \mathrm{~s}$. The inset on right-bottom displays original $\mathrm{I}_{\mathrm{to}}$ current traces in control conditions and in the presence of the solvent $(0.1 \%$ DMSO). Dashed lines indicate zero current levels. Data are expressed as means \pm SEM
2017), and this may further increase the risk for arrhythmia development.

Moreover, when CBD intake is combined with pharmacological agents affecting cardiac repolarization, as well as in certain pathophysiological situations such as hypokalemia, or diseases like LQT syndrome, diabetes mellitus, HCM or heart failure where cardiac repolarization reserve (Varró and Baczkó 2011) or drug metabolism is impaired, CBD can have an additive effect, further increasing the proarrhythmic risk and the possible incidence of sudden cardiac death. Such additive interactions were reported both in animal experimental (Lengyel et al. 2007) and clinical settings (Wisniowska et al. 2016). The cardiovascular effects of CBD may only partly be attributed to its effects on transmembrane ion channels, the cardiovascular safety of this compound may be influenced by its activities on other targets, and by the presence of myocardial ischemia (Ferdinandy et al. 2019) as well. Therefore, further studies are needed to assess the unwanted cardiovascular effects of CBD and other cannabinoids both in vivo and in vitro studies, with special focus on the benefit-risk assessment of products with different cannabinoid content.
Fig. 7 Lack of effect of CBD on the inward rectifier potassium current in rabbit left ventricular myocytes. The panel shows steady-state current-voltage curves for $\mathrm{I}_{\mathrm{K} 1}$ in control conditions and after application of $10 \mu \mathrm{M} \mathrm{CBD}$ in rabbit left ventricular myocytes. Inset indicates the voltage protocol. Data are expressed as means \pm SEM

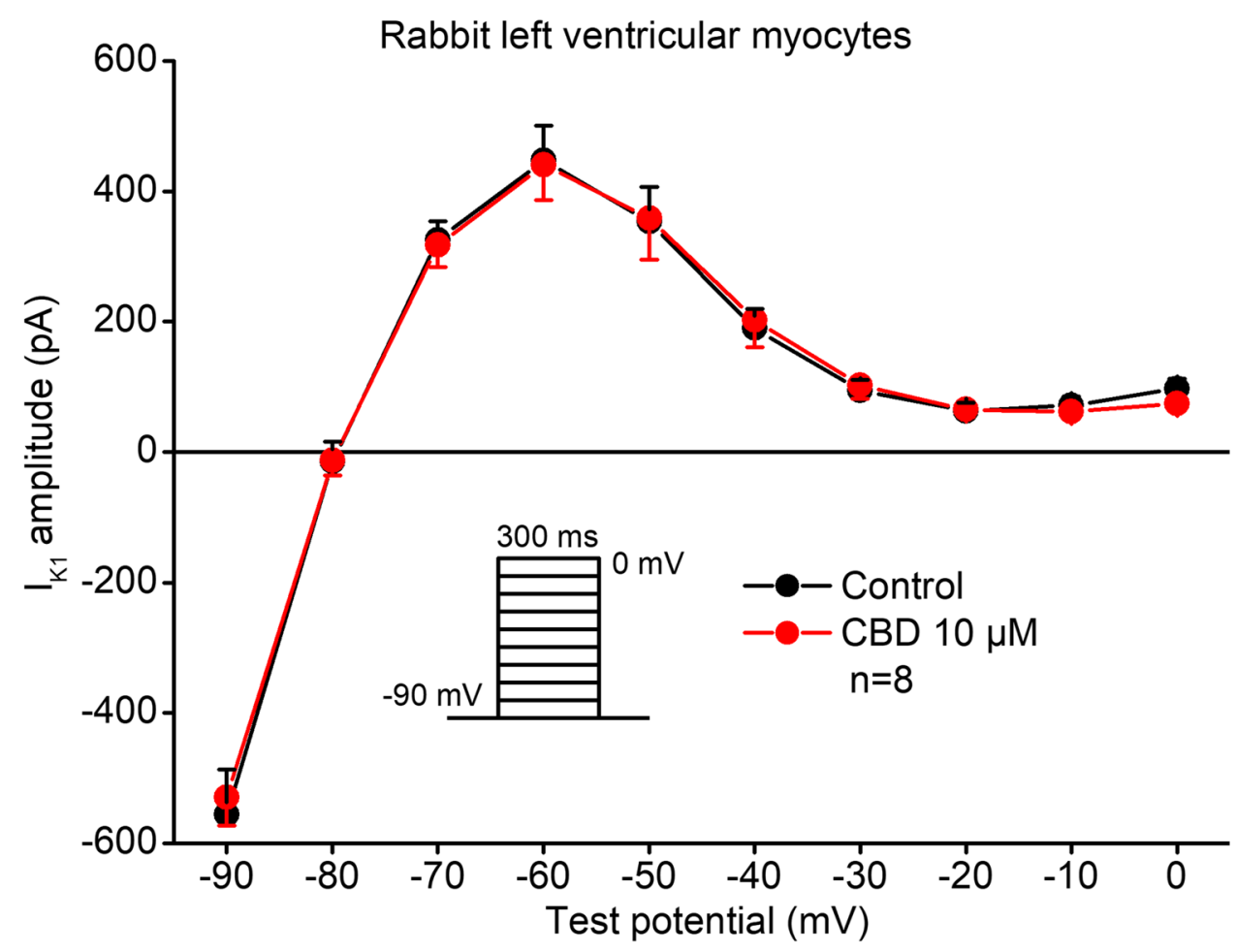


Author contributions DC, LV, IB, NJ and AV conceived the experiment, LT, MN, PO, BP, JP, BC-L, TK and AB conducted the experiment(s), LT, MN, PO, BP, JP, BC-L, TK, AB and LV analysed the results, DC, LV, IB, NJ and AV, prepared the manuscript. All authors reviewed the manuscript.

Funding Open access funding provided by University of Szeged. Financial support from the Economic Development and Innovation Operative Programme GINOP-2.3.2-15-2016-00012, the National Research Development and Innovation Office (NKFIH K 135464 and NKFIH K 128851), the Ministry of Human Capacities Hungary (20391-3/2018/FEKUSTRAT and EFOP-3.6.2-16-201700006), and from the Eötvös Loránd Research Network are gratefully acknowledged.

Data availability The data underlying this article will be shared on reasonable request to the corresponding author.

\section{Declarations}

Conflict of interest The authors declare that they have no conflict of interest.

Ethical approval All experiments were carried out in compliance with the Guide for the Care and Use of Laboratory Animals (USA NIH publication NO 85-23, revised 1996) and conformed to the Directive 2010/63/EU of the European Parliament. The protocols have been approved by the Ethical Committee for the Protection of Animals in Research of the University of Szeged, Szeged, Hungary (approval numbers: I-74-15-2017 and I-74-24-2017) and by the Department of Animal Health and Food Control of the Ministry of Agriculture and Rural Development (authority approval numbers XIII/3330/2017 and XIII/3331/2017).

Open Access This article is licensed under a Creative Commons Attribution 4.0 International License, which permits use, sharing, adaptation, distribution and reproduction in any medium or format, as long as you give appropriate credit to the original author(s) and the source, provide a link to the Creative Commons licence, and indicate if changes were made. The images or other third party material in this article are included in the article's Creative Commons licence, unless indicated otherwise in a credit line to the material. If material is not included in the article's Creative Commons licence and your intended use is not permitted by statutory regulation or exceeds the permitted use, you will need to obtain permission directly from the copyright holder. To view a copy of this licence, visit http://creativecommons.org/licenses/by/4.0/.

\section{References}

Al Kury LT, Voitychuk OI, Yang KH, Thayyullathil FT, Doroshenko P, Ramez AM et al (2014) Effects of the endogenous cannabinoid anandamide on voltage-dependent sodium and calcium channels in rat ventricular myocytes. Br J Pharmacol 171:3485-3498

Amoros I, Barana A, Caballero R, Gómez R, Osuna L, Lillo MP et al (2010) Endocannabinoids and cannabinoid analogues block human cardiac Kv4.3 channels in a receptor-independent manner. J Mol Cell Cardiol 48:201-210

Barana A, Amoros I, Caballero R, Gómez R, Osuna L, Lillo MP et al (2010) Endocannabinoids and cannabinoid analogues block cardiac hKv1.5 channels in a cannabinoid receptor-independent manner. Cardiovasc Res 85:56-67
Christian F, Szaszák M, Friedl S, Drewianka S, Lorenz D, Goncalves A et al (2011) Small molecule AKAP-protein kinase A (PKA) interaction disruptors that activate PKA interfere with compartmentalized cAMP signaling in cardiac myocytes. J Biol Chem 286(11):9079-9096. https://doi.org/10.1074/jbc.M110.160614

Courts J, Maskill V, Gray A, Glue P (2016) Signs and symptoms associated with synthetic cannabinoid toxicity: systematic review. Australas Psychiatry 24:598-601

Czégény Z, Nagy G, Babinszki B, Bajtel Á, Sebestyén Z, Kiss T, Csupor-Löffler B, Tóth B, Csupor D (2021) CBD, a precursor of THC in e-cigarettes. Sci Rep 11(1):8951. https://doi.org/10.1038/ s41598-021-88389-z

Ferdinandy P, Baczkó I, Bencsik P, Giricz Z, Görbe A, Pacher P et al (2019) Definition of hidden drug cardiotoxicity: paradigm change in cardiac safety testing and its clinical implications. Eur Heart J 40(22):1771-1777. https://doi.org/10.1093/eurheartj/ehy365

Fraguas-Sánche AI, Torres-Suárez AI (2018) Medical use of cannabinoids. Drugs 78(16):1665-1703. https://doi.org/10.1007/ s40265-018-0996-1

Ghovanloo MR, Shuart NG, Mezeyova J, Dean RA, Ruben PC, Goodchild SJ (2018) Inhibitory effects of cannabidiol on voltagedependent sodium currents. J Biol Chem 293:16546-16558

Han W, Bao W, Wang Z, Nattel S (2002) Comparison of ion-channel subunit expression in canine cardiac Purkinje fibers and ventricular muscle. Circ Res 91(9):790-797. https://doi.org/10.1161/01. res.0000039534.18114.d9

Iffland K, Grotenhermen F (2017) An update on safety and side effects of cannabidiol: a review of clinical data and relevant animal studies. Cannabis Cannabinoid Res 2:139-154

Jost N, Nagy N, Corici C, Kohajda Z, Horváth A, Acsai K et al (2013) ORM-10103, a novel specific inhibitor of the $\mathrm{Na}^{+} / \mathrm{Ca}^{2+}$ exchanger, decreases early and delayed after depolarizations in the canine heart. Br J Pharmacol 170(4):768-778. https://doi.org/10.1111/ bph. 12228

Kalla A, Krishnamoorthy PM, Gopalakrishnan A, Figueredo VM (2018) Cannabis use predicts risks of heart failure and cerebrovascular accidents: results from the National Inpatient Sample. J Cardiovasc Med (hagerstown) 19:480-484

Lengyel C, Varro A, Tabori K, Papp JG, Baczko I (2007) Combined pharmacological block of $\mathrm{I}(\mathrm{Kr})$ and $\mathrm{I}(\mathrm{Ks})$ increases short-term QT interval variability and provokes torsades de pointes. Br J Pharmacol 151:941-951

Li Q, Ma HJ, Song SL, Shi M, Ma HJ, Li DP, Zhang Y (2012) Effects of anandamide on potassium channels in rat ventricular myocytes: a suppression of I(to) and augmentation of K(ATP) channels. Am J Physiol Cell Physiol 302:C924-C930

Manolis TA, Manolis AA, Manolis AS (2019) Cannabis associated 'high' cardiovascular morbidity and mortality: marijuana smoke like tobacco smoke? A deja vu/deja vecu story? Mini Rev Med Chem 19:870-879

Millar SA, Stone NL, Yates AS, O'Sullivan SE (2018) A Systematic review on the pharmacokinetics of cannabidiol in humans. Front Pharmacol 9:1365

Mittleman MA, Lewis RA, Maclure M, Sherwood JB, Muller JE (2001) Triggering myocardial infarction by marijuana. Circulation 103:2805-2809

Orvos P, Kohajda Z, Szlovák J, Gazdag P, Árpádffy-Lovas T, Tóth D et al (2019) Evaluation of possible proarrhythmic potency: comparison of the effect of dofetilide, cisapride, sotalol, terfenadine, and verapamil on hERG and native IKr currents and on cardiac action potential. Toxicol Sci 168(2):365-380. https://doi.org/10. 1093/toxsci/kfy299

Orvos P, Pászti B, Topal L, Gazdag P, Prorok J, Polyák A et al (2020) The electrophysiological effect of cannabidiol on hERG current and in guinea-pig and rabbit cardiac preparations. Sci Rep 10(1):16079. https://doi.org/10.1038/s41598-020-73165-2 
Ozturk HM, Yetkin E, Ozturk S (2019) Synthetic cannabinoids and cardiac arrhythmia risk: review of the literature. Cardiovasc Toxicol 19:191-197

Pacher P, Steffens S, Hasko G, Schindler TH, Kunos G (2018) Cardiovascular effects of marijuana and synthetic cannabinoids: the good, the bad, and the ugly. Nat Rev Cardiol 15:151-166

Redfern W, Carlsson L, Davis AS, Lynch WG, MacKenzie I, Palethorpe $S$ et al (2003) Relationships between preclinical cardiac electrophysiology, clinical QT interval prolongation and torsade de pointes for a broad range of drugs: evidence for a provisional safety margin in drug development. Cardiovasc Res 58:32-45

Roden DM, Hoffman BF (1985) Action potential prolongation and induction of abnormal automaticity by low quinidine concentrations in canine Purkinje fibers. Relationship to potassium and cycle length. Circ Res 56:857-867

Sanguinetti MC, Tristani-Firouzi M (2006) hERG potassium channels and cardiac arrhythmia. Nature 440:463-469

Sellers EM, Schoedel K, Bartlett C, Romach M, Russo EB, Stott CG et al (2013) A multiple-dose, randomized, double-blind, placebocontrolled, parallel-group QT/QTc study to evaluate the electrophysiologic effects of THC/CBD spray. Clin Pharmacol Drug Dev 2:285-294

Serpell MG, Notcutt W, Collin C (2013) Sativex long-term use: an open-label trial in patients with spasticity due to multiple sclerosis. J Neurol 260:285-295

Sierra S, Luquin N, Navarro-Otano J (2018) The endocannabinoid system in cardiovascular function: novel insights and clinical implications. Clin Auton Res 28(1):35-52. https://doi.org/10.1007/ s10286-017-0488-5

Singh SM, Koh M, Fang J, Ko DT (2019) The risk of cardiovascular events on cannabis' highest day. Can J Cardiol 35:1589-1591
Varro A, Elharrar V, Surawicz B (1985) Effect of antiarrhythmic drugs on the premature action potential duration in canine cardiac Purkinje fibers. J Pharmacol Exp Ther 233:304-311

Varró A, Baczkó I (2011) Cardiac ventricular repolarization reserve: a principle for understanding drug-related proarrhythmic risk. $\mathrm{Br}$ J Pharmacol 164(1):14-36. https://doi.org/10.1111/j.1476-5381. 2011.01367.x

Wang Z, Feng J, Shi H, Pond A, Nerbonne JM, Nattel S (1999) Potential molecular basis of different physiological properties of the transient outward $\mathrm{K}+$ current in rabbit and human atrial myocytes. Circ Res 84(5):551-561. https://doi.org/10.1161/01.res.84.5.551

Wisniowska B, Tylutki Z, Wyszogrodzka G, Polak S (2016) Drugdrug interactions and QT prolongation as a commonly assessed cardiac effect - comprehensive overview of clinical trials. BMC Pharmacol Toxicol 17:12

Yun J, Yoon KS, Lee TH, Lee H, Gu SM, Song YJ et al (2016) Synthetic cannabinoid, JWH-030, induces QT prolongation through hERG channel inhibition. Toxicol Res (camb) 5:1663-1671

Zicha S, Xiao L, Stafford S, Cha TJ, Han W, Varro A, Nattel S (2004) Transmural expression of transient outward potassium current subunits in normal and failing canine and human hearts. J Physiol 561(Pt 3):735-748. https://doi.org/10.1113/jphysiol.2004.075861

Publisher's Note Springer Nature remains neutral with regard to jurisdictional claims in published maps and institutional affiliations. 